NOTE

\title{
Comparison of PCR methods for the detection of genetic variants of carp edema virus
}

\author{
Mikolaj Adamek ${ }^{1, *}$, Marek Matras ${ }^{2}$, Verena Jung-Schroers ${ }^{1}$, Felix Teitge ${ }^{1}$, \\ Max Heling ${ }^{1}$, Sven M. Bergmann ${ }^{3}$, Michal Reichert ${ }^{2}$, Keith Way ${ }^{4}$, \\ David M. Stone ${ }^{4}$, Dieter Steinhagen ${ }^{1}$
}

${ }^{1}$ Fish Disease Research Unit, Institute for Parasitology, University of Veterinary Medicine, Bünteweg 17, 30559 Hannover, Germany ${ }^{2}$ Laboratory of Fish Diseases, National Veterinary Research Institute, Partyzantów 57, 24-100 Puławy, Poland

${ }^{3}$ Institute of Infectology, Friedrich-Loeffler-Institut, Südufer 10, 17498 Greifswald-Insel Riems, Germany

${ }^{4}$ Centre for Environment, Fisheries and Aquaculture Science (CEFAS), Weymouth, Dorset, DT4 8UB, UK

\begin{abstract}
The infection of common carp and its ornamental variety, koi, with the carp edema virus (CEV) is often associated with the occurrence of a clinical disease called 'koi sleepy disease'. The disease may lead to high mortality in both koi and common carp populations. To prevent further spread of the infection and the disease, a reliable detection method for this virus is required. However, the high genetic variability of the CEV p4a gene used for PCR-based diagnostics could be a serious obstacle for successful and reliable detection of virus infection in field samples. By analysing 39 field samples from different geographical origins obtained from koi and farmed carp and from all 3 genogroups of CEV, using several recently available PCR protocols, we investigated which of the protocols would allow the detection of CEV from all known genogroups present in samples from Central European carp or koi populations. The comparison of 5 different PCR protocols showed that the PCR assays (both end-point and quantitative) developed in the Centre for Environment, Fisheries and Aquaculture Science exhibited the highest analytical inclusivity and diagnostic sensitivity. Currently, this makes them the most suitable protocols for detecting viruses from all known CEV genogroups.
\end{abstract}

KEY WORDS: Carp edema virus $\cdot$ Koi sleepy disease $\cdot$ PCR $\cdot$ Common carp $\cdot$ Koi

\section{INTRODUCTION}

The infection of common carp and its ornamental variety, the koi, with the carp edema virus (CEV) is often associated with the occurrence of a clinical disease called 'koi sleepy disease' (KSD) (Way \& Stone 2013). The virus mainly affects the gills of infected fish, where it causes epithelial lesions and oedema (Miyazaki et al. 2005). The disease is associated with lethargic behaviour, with affected individuals characteristically lying at the bottom of the tank. The disease may lead to a high

*Corresponding author: mikolaj.adamek@tiho-hannover.de mortality in both koi and common carp populations (Way \& Stone 2013, Bachmann \& Keilholz 2016). The number of countries in which infections with CEV and outbreaks of KSD were detected in carp or koi has been rising rapidly over the last several years. Currently, the virus has been recorded in several European countries (Way \& Stone 2013, Jung-Schroers et al. 2015, Lewisch et al. 2015, Matras et al. 2017), the USA (Hedrick et al. 1997), and from at least 3 countries in Asia: Japan (Oyamatsu et al. 1997), India (Swaminathan et al. 2016) and China (Zhang et al. 2017).

(C) The authors 2017. Open Access under Creative Commons by Attribution Licence. Use, distribution and reproduction are unrestricted. Authors and original publication must be credited. 
Information on $\mathrm{CEV}$ is scarce. Several electron microscope images have documented poxvirus-like particles in the infected gill epithelium (Miyazaki et al. 2005). However, despite many attempts, the cultivation of $\mathrm{CEV}$ in vitro has not been successful employing the fish cell lines presently available (Jung-Schroers et al. 2015, Lewisch et al. 2015, Swaminathan et al. 2016). Genomic data of the virus is limited to the fragment of the DNA sequence encoding the core protein P4a (Oyamatsu 1996, Matras et al. 2017), but a comparison of CEV sequences retrieved from diseased fish from various locations in Europe and Asia (see Table 1, and Fig. S1 in the Supplement at www.int-res.com/articles/suppl/d126p075 _supp.pdf) revealed a 6 to $10 \%$ degree of genetic diversity depending on the fragment of the $p 4 a$ gene. The analyses allowed recognition of up to 3 different genetic lineages or genogroups (Matras et al. 2017). During a large epidemiological study conducted in Germany, we collected and sequenced over 150 CEV-positive samples (M. Heling et al. unpubl. data). With an increasing number of sequences available, the significant diversity of $\mathrm{CEV}$, which already was described by Matras et al. (2017), became more apparent.

Because of its wide distribution and potential virulence, CEV is considered a potential risk for the koi trade and for global carp aquaculture. In order to prevent further spread of the infection and the disease, a reliable detection method for this virus is required. Because in vitro cultivation of $\mathrm{CEV}$ is not feasible with currently available fish cell lines, a CEV infection cannot be detected by re-isolation in cells, but relies on the detection of CEV-specific DNA sequences by PCR or finding virus particles by means of electron microscopy. For a long time only one end-point PCR protocol (designed by Oyamatsu et al. 1997) was available, based on virus-specific sequences obtained from infected koi in Japan. Recently, additional end-point and quantitative PCR protocols have been published, including assays developed at the Centre for Environment, Fisheries and Aquaculture Science (CEFAS) based on CEV sequences in samples obtained from koi and common carp in the UK (Matras et al. 2017), and a qPCR assay developed at the University of Veterinary Medicine in Hannover (TiHo) based on CEV sequences from koi in Germany (Adamek et al. 2016).

The high genetic variability of the CEV $p 4 a$ gene used for designing all the PCR assays could be a serious obstacle for successful and reliable detection of virus infection in field samples, when an assay employing a double label probe is used. This became evident when samples from common carp with clinical KSD produced negative results during analysis by means of the qPCR assay based on a dual labelled probe published by Adamek et al. (2016) and the end-point PCR by Oyamatsu et al. (1997). These PCR protocols were developed on $p 4 a$ sequence information of CEV from koi (CEV genogroup IIa) and apparently did not allow the detection of the infection in samples from KSD-affected farmed common carp (CEV genogroup I). In farmed carp, a CEV infection was confirmed using the PCR assay reported by Matras et al. (2017). Therefore, we decided to evaluate which of the available PCR assays would be able to detect all the virus variants present in the field. By analysing various field samples from different origins with several PCR protocols, we investigated which of the protocols would allow the detection of CEV from all known genogroups present in samples from Central European carp or koi populations as a step towards the determination of the analytical specificity of these tests.

\section{MATERIALS AND METHODS}

\section{Samples}

To determine if samples containing CEV from different carp varieties or virus genogroups could be detected by the different PCR assays available, 39 field samples were selected from a total of 139 samples (Table 1). These 139 field samples had been found positive for CEV by analysis using at least one of the compared PCR methods, and after sequencing products from the CEFAS end-point PCR, were found infected with $39 \mathrm{CEV}$ variants which differ in their DNA sequences encoding for a P4a core protein fragment. The samples were collected from carp or koi in Poland (Matras et al. 2017) and Germany between 2011 and 2016. In some cases, fish were sampled directly after import from Japan (Table 1). If more than one fish was infected with a certain CEV variant, a sample representing this variant was selected randomly. The DNA concentration of all samples was measured with a Nanodrop ND1000 (PeqLab) photometer diluted with PCR-grade water (ThermoFisher Scientific) to a working concentration of $50 \mathrm{ng}$ $\mu^{-1}$. As a part of the currently presented comparison, the PCR products obtained using the CEFAS (nested) end-point PCR were re-sequenced to confirm that they carried unique CEV p4a sequences. Using both forward and reverse primers, the overlapping $357 \mathrm{bp}$ sequence of the CEV-specific DNA fragment was 
Table 1. Samples, sequence variants, their genogroup, country of origin and other countries (D: Germany; PL: Poland; UK: United Kingdom; J: Japan), number of fish individuals and fish species or variety in which carp edema virus with the selected sequences was detected. ${ }^{\prime * \prime}$ indicates that the sequence was obtained from some fish imported from Japan

\begin{tabular}{|c|c|c|c|c|c|}
\hline $\begin{array}{l}\text { Sample no./ } \\
\text { Sequence } \\
\text { variant }\end{array}$ & $\begin{array}{c}\text { Sequence } \\
\text { GenBank } \\
\text { ID }\end{array}$ & $\begin{array}{l}\text { Geno- } \\
\text { group }\end{array}$ & $\begin{array}{l}\text { Country of } \\
\text { origin; other } \\
\text { countries }\end{array}$ & $\begin{array}{c}\text { No. of } \\
\text { fish with } \\
\text { sequence }\end{array}$ & $\begin{array}{l}\text { Species or } \\
\text { variety }\end{array}$ \\
\hline 1 & KX254012 & I & PL & 1 & Common carp \\
\hline 2 & KY550409 & I & $\mathrm{D}$ & 2 & Common carp \\
\hline 3 & KY550410 & I & $\mathrm{D} ; \mathrm{PL}$ & 2 & Common carp \\
\hline 4 & KY550411 & I & $\mathrm{D}_{i} \mathrm{PL}$ & 10 & Common carp \\
\hline 5 & KY550412 & I & $\mathrm{D}$ & 3 & Common carp \\
\hline 6 & KX253998 & I & PL & 1 & Common carp \\
\hline 7 & KY550413 & I & $\mathrm{D}$ & 2 & Common carp \\
\hline 8 & KY550414 & I & $\mathrm{D}$ & 1 & Common carp \\
\hline 9 & KY550415 & I & $\mathrm{D}$ & 2 & Common carp \\
\hline 10 & KY550416 & I & D & 1 & Common carp \\
\hline 11 & KY550417 & I & $\mathrm{D}_{i} \mathrm{PL}, \mathrm{UK}$ & 34 & $\begin{array}{l}\text { Common carp, } \\
\text { pike-perch }\end{array}$ \\
\hline 12 & KX254007 & I & PL & 1 & Common carp \\
\hline 13 & KY550418 & I & $\mathrm{D} ; \mathrm{PL}$ & 2 & Common carp \\
\hline 14 & KX254010 & I & PL & 1 & Common carp \\
\hline 15 & KX254008 & I & PL & 1 & Common carp \\
\hline 16 & KX254005 & IIb & PL & 3 & Common carp \\
\hline 17 & KY550419 & IIb & $\mathrm{D}$ & 2 & Koi \\
\hline 18 & KY550420 & IIa & $\mathrm{D}$ & 1 & Koi \\
\hline 19 & KX254004 & IIa & PL & 1 & Koi \\
\hline 20 & KY550421 & IIa & $\mathrm{D}$ & 1 & Koi \\
\hline 21 & KY550422 & IIa & $\mathrm{D}$ & 2 & Koi \\
\hline 22 & KY550423 & IIa & $\mathrm{D}$ & 1 & Koi \\
\hline 23 & KY550424 & IIa & $\mathrm{D}_{i} \mathrm{UK}$ & 14 & Koi \\
\hline 24 & KY550425 & IIa & D & 2 & Koi \\
\hline 25 & KY550426 & IIa & $\mathrm{D}$ & 1 & Koi \\
\hline 26 & KY550427 & IIa & $\mathrm{D}$ & 2 & Koi \\
\hline 27 & KY550428 & IIa & $\mathrm{D}$ & 7 & Koi \\
\hline 28 & KY550429 & IIa & $\mathrm{D}$ & 2 & Koi \\
\hline 29 & KY550430 & IIa & $\mathrm{D}$ & 1 & Koi \\
\hline 30 & KY550431 & IIa & $\mathrm{D}$ & 1 & Koi \\
\hline 31 & KY550432 & IIa & D & 1 & Koi \\
\hline 32 & KY550433 & IIa & $D_{i} J^{*}$ & 14 & Koi \\
\hline 33 & KY550434 & IIa & $\mathrm{D}$ & 1 & Koi \\
\hline 34 & KY550435 & IIa & $\mathrm{D}$ & 1 & Koi \\
\hline 35 & KY550436 & IIa & $\mathrm{D}$ & 1 & Koi \\
\hline 36 & KY550437 & IIa & $\mathrm{D}$ & 9 & Koi, common carp \\
\hline 37 & KY550438 & IIa & $\mathrm{D}$ & 1 & Koi \\
\hline 38 & KX253997 & IIa & PL & 1 & Common carp \\
\hline 39 & KY550439 & IIa & $\mathrm{D}$ & 5 & Koi \\
\hline
\end{tabular}

obtained by means of Sanger sequencing, performed by LGC Genomics (Berlin).

\section{Phylogeny}

The overlapping sequences obtained from the samples were trimmed to 357 bp (location indicated in Fig. S1 in the Supplement) and were analysed with the tools available at www.phylogeny.fr (Dereeper et al. 2008). Sequences were aligned with MUSCLE, and curated with Gblocks. Phylogenetic analyses (based on maximum likelihood) were performed with PhyML. Finally, a phylogenetic tree was rendered with TreeDyn.

\section{CEV detection}

Five different PCR protocols were used for detection of CEV-specific DNA: (1) the end-point PCR designed by Oyamatsu et al. (1997), (2) the CEFAS end-point PCR assay developed by CEFAS and published by Matras et al. (2017), (3) the CEFAS quantitative (probe) PCR assay published by Matras et al. (2017), (4) the TiHo quantitative (probe) PCR assay published by Adamek et al. (2016), and (5) a TiHo SYBRGreen quantitative PCR assay designed by Adamek et al. (2017). Primer sequences are presented in Table 2 and the location of the primers within the p4a gene fragment is indicated in Fig. S1.

All PCRs were run at the same time with a template which had not experienced repeated freezing-thawing cycles between the runs of the different PCR assays. Apart from CEV-positive samples, non-template controls (NTCs) and 2 CEV-negative samples were included from specific pathogen free (SPF) koi and SPF common carp to insure the lack of intra-laboratory contaminations. The end-point assays were performed using the KAPA2G Robust Hot Start PCR kit (Peqlab) according to the manufacturer's instructions. The reaction mix was prepared as follows: $1 \times$ KAPA2G buffer A, $0.2 \mu \mathrm{M}$ of each primer, $0.2 \mathrm{mM}$ of each dNTP, $1 \mathrm{U}$ of KAPA2G Robust Hot Start Polymerase, $5.0 \mu \mathrm{l}$ of DNA (50 ng $\mathrm{\mu l}^{-1}$ ) and nuclease-free water to a final volume of $20 \mu$. The amplification program included an initial denaturation at $95^{\circ} \mathrm{C}$ for $5 \mathrm{~min}$, followed by 45 cycles of denaturation at $95^{\circ} \mathrm{C}$ for $30 \mathrm{~s}$, annealing at $55^{\circ} \mathrm{C}$ for $30 \mathrm{~s}$ and elongation at $72^{\circ} \mathrm{C}$ for $30 \mathrm{~s}$. A final elongation step for $7 \mathrm{~min}$ at $72^{\circ} \mathrm{C}$ was performed at the end of each run. If needed, a nested reaction was per- 
Table 2. Sequences of PCR primers and probes compared in this study

\begin{tabular}{|lll|}
\hline PCR name & Oligo name & Sequence $\left(5^{\prime}-3^{\prime}\right)$ \\
\hline CEFAS end-point & CEFAS_F & ATG GAG TAT CCA AAG TAC TTA G \\
CEFAS nested end-point & CEFAS_R & CTC TTC ACT ATT GTG ACT TTG \\
& CEFAS_nF & GTT ATC AAT GAA ATT TGT GTA TTG \\
CEFAS probe qPCR & CEFAS_nR & TAG CAA AGT ACT ACC TCA TCC \\
& CEFAS_qF & AGT TTT GTA KAT TGT AGC ATT TCC \\
& CEFAS_qR & GAT TCC TCA AGG AGT TDC AGT AAA \\
TiHo probe qPCR & CEFAS_q_Probe & [FAM] AGA GTT TGT TTC TTG CCA TAC AAA CT [BHQ1] \\
& TiHo_qF & TTT AGG AGG ACA AGT AAA GTT ACC A \\
TiHo SYBRGreen qPCR & TiHo_qR & GCA AGT TAT TTC GAT GCC AAC C \\
& TiHo_q_Probe & [FAM] CCA GCT CCT ACA AGG AAA GCA ATT GA [BHQ1] \\
& TiHo_Sybr_qF & CAT TTC CTA GTT TGT ATG GCA AG \\
Oyamatsu end-point & TiHo_Sybr_qR & TGA TGA TTG GAA TAA GAT GTC TGT C \\
& Oyamatsu_F & GCT GTT GCA ACC ATT TGA GA \\
Oyamatsu nested end-point & Oyamatsu_R & TGC AGG TTG CTC CTA ATC CT \\
& Oyamatsu_nF & GCT GCT GCA CTT TTA GGA GG \\
& Oyamatsu_nR & TGC AAG TTA TTT CGA TGC CA \\
\hline
\end{tabular}

formed (with nested primers and the same reaction setup) for samples which were negative in the first round of reactions. As a template for nested PCR, $5 \mu \mathrm{l}$ of 100x diluted PCR mix from the first round of reaction was used. All end-point PCR assays were performed in duplicate for each sample using a Sensoquest LabCycler (Sensoquest). The results were visualised by $302 \mathrm{~nm}$ UV light screening after electrophoretic separation of the amplicons in a $1 \%$ agarose gel containing $1 \times$ Gel Red (Biotium) fluorescent DNA stain.

The reaction mix for the TiHo probe qPCR assay described by Adamek et al. (2016) contained 1x Maxima Probe qPCR Mastermix (Thermo Fisher Scientific), $900 \mathrm{nM}$ of each primer, $300 \mathrm{nM}$ of the probe, $5 \mu$ of template DNA (50 $\mathrm{ng} \mathrm{\mu l}^{-1}$ ) and nuclease-free water to a final volume of $20 \mu \mathrm{l}$. The reaction mix for the qPCR assay developed from CEFAS (taken from Matras et al. 2017) contained 1× Maxima Probe qPCR Mastermix (Thermo Fisher Scientific), 500 nM of each primer, $200 \mathrm{nM}$ of the probe, $5 \mu \mathrm{l}$ of template DNA and nuclease-free water to a final volume of $20 \mu \mathrm{l}$. The amplification program for both assays included an initial denaturation at $95^{\circ} \mathrm{C}$ for $10 \mathrm{~min}$, followed by 40 cycles of denaturation at $95^{\circ} \mathrm{C}$ for $30 \mathrm{~s}$ and annealing at $60^{\circ} \mathrm{C}$ for $30 \mathrm{~s}$.

The quantitative PCR with TiHo SYBRGreen based detection of the amplicon was prepared as follows: 1× Maxima SYBR Green mastermix (with $10 \mathrm{nM}$ of ROX), $0.2 \mu \mathrm{M}$ of each primer, $5.0 \mu \mathrm{l}$ of DNA (50 ng $\mathrm{ul}^{-1}$ ) and nuclease-free water to a final volume of $20 \mu \mathrm{l}$. The amplification program included an initial denaturation at $95^{\circ} \mathrm{C}$ for $10 \mathrm{~min}$, followed by 40 cycles of denaturation at $95^{\circ} \mathrm{C}$ for $30 \mathrm{~s}$, annealing at $55^{\circ} \mathrm{C}$ for $30 \mathrm{~s}$ and elongation at $72^{\circ} \mathrm{C}$ for $30 \mathrm{~s}$. A dissociation curve was performed at the end of each run; results with a single melting peak over $75^{\circ} \mathrm{C}$ were considered positive.

All qPCR assays were performed in duplicates for each sample using a Stratagene Mx3005P cycler (Agilent). The probe based qPCRs were run simultaneously on the same plate. For all qPCR assays the cycle threshold $\left(C_{\mathrm{T}}\right)$ values were read at a threshold of 0.05 of normalised fluorescence change (dRn). Information on the analytical sensitivity of the TiHo probe quantitative PCR and the TiHo SYBRGreen PCR is given in Adamek et al. (2016, 2017). Currently, all quantitative PCRs (including CEFAS) are routinely run with supercoiled plasmid standards ranging from $10^{7}$ to $10^{1}$ copies of CEV p4a gene (see Fig. S2 in the Supplement) and are able to detect samples below 10 copies of the p4a gene.

\section{RESULTS AND DISCUSSION}

All field samples that produced CEV-positive results by Oyamatsu's end-point PCR, the real-time PCR assay published by Adamek et al. (2016) (TiHo probe qPCR in Fig. 1) or the TiHo SYBRGreen PCR assay were also positive when analysed by the CEFAS end-point or qPCRs (Fig. 1). In addition, the PCR assays designed by CEFAS detected CEV-specific DNA in further samples, which were negative or gave multiple bands when analysed by means of Oyamatsu's PCR assay or the TiHo probe qPCR assay 


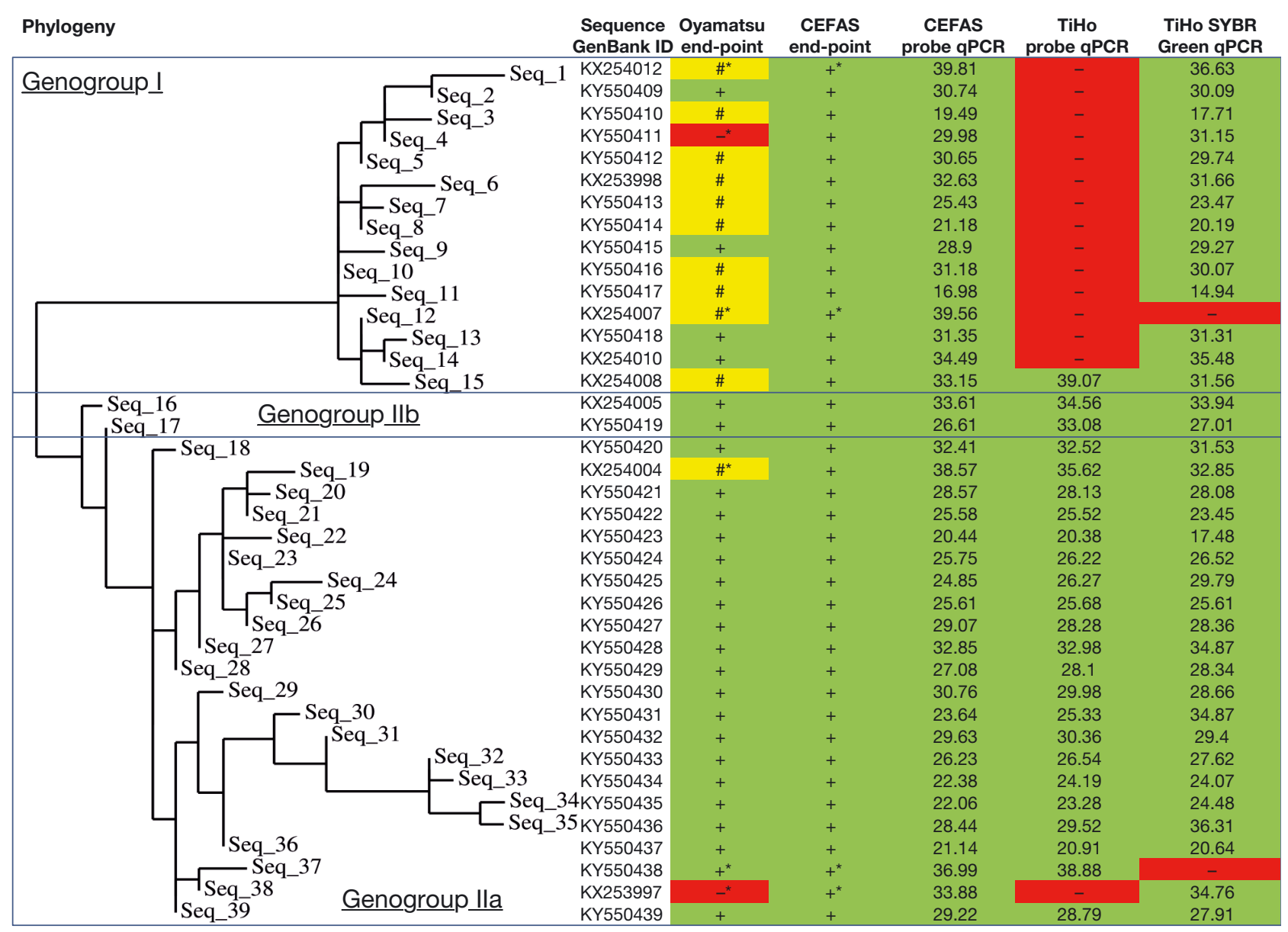

0.09

Fig. 1. Phylogenic (PhyML) analysis of the 357 bp nucleotide sequence encoding the carp edema virus (CEV) P4a core protein. This analysis presents a subset of the sequences obtained during an epidemiological study performed in Germany (this study), Poland and the UK (Matras et al. 2017) into 3 genogroups. The branch length is proportional to the number of substitutions per site. Given are (1) $C_{\mathrm{T}}$ values based on delta fluorescence (dR) data obtained in the quantitative PCR protocols tested on CEVpositive samples and (2) a comparison of the specificity and sensitivity of the qPCRs to the end-point PCR protocols. '+' and green colour: positive signal in the $\mathrm{PCR}_{i}{ }^{\prime}-{ }^{\prime}$ and red colour: negative PCR result. '*' indicates the use of nested end-point PCR was needed. '\#' and yellow colour indicate the presence of multiple bands in an end-point PCR

(Fig. 1). The CEFAS end-point PCR assay did not produce any additional non-specific band which could hamper the interpretation of the result or sequencing of the amplicon. No PCR assays produced an amplicon in NTCs or in negative control samples.

When the amplicons received from the CEFAS end-point PCR assay for all 39 samples were resequenced, each was confirmed as bearing a unique sequence of a $357 \mathrm{bp}$ long DNA fragment, which then was used for phylogenetic analysis. The phylogenetic analysis (Fig. 1) indicated that 15 samples constitute one clade (genogroup I), and all these samples were collected from farmed common carp. In one case the same sequence was also obtained from samples of a pike-perch Sander lucioperca which did not show any symptoms of KSD and which was collected from a pond with a massive outbreak of clinical KSD in common carp (Table 1). We suspect that virus shed from carp suffering from this KSD outbreak most likely resulted in a biological contamination of the gills of the pike-perch. The sequences from genogroup I were clearly separated from 22 sequences forming genogroup IIa, which were mostly (but not exclusively) obtained from koi samples (Fig. 1, Table 1). Between these 2 genogroups, 2 sequences were assigned to a new genogroup (genogroup IIb). One of these sequences was obtained from 3 common carp from Poland; the second was recorded from 2 koi from Germany (Table 1). The findings of our phylogenetic analysis support the genetic distribu- 
tion of the samples as proposed by Matras et al. (2017), with separation into genogroups I, IIa and IIb.

This phylogenetic analysis was also used to determine which genogroups of CEV would be detected by the protocols applied. As with the CEFAS endpoint PCR assay, CEV was detected in all samples by means of the qPCR assay designed by CEFAS, and when the virus load was quantified, the $C_{\mathrm{T}}$ values were in the same range as those obtained using any of the other quantitative assays applied (Fig. 1). Only in one sample did the CEFAS qPCR assay resulted in a $C_{\mathrm{T}}$ value (38.57) that was more than 5 cycles higher than when this sample was analysed with the TiHo SYBRGreen quantitative assay.

Oyamatsu's end-point PCR assay (Oyamatsu et al. 1997) worked well with samples positive for CEV from genogroups IIa and IIb. However, multiple bands were present in samples positive for CEV from genogroup I, which made interpretation of these results difficult. This, however unlikely, could be related to an off-target attachment of the primers to the common carp genome. This phenomenon did not occur in the negative controls employed. Our findings confirm earlier results (Adamek et al. 2016), which already indicated that this PCR does not reliably amplify DNA of CEV from genogroup I. Furthermore, with 2 samples containing CEV DNA, this PCR gave a negative result.

The probe-based TiHo qPCR assay provided 14 false-negative results from carp infected with CEV from genogroup I and from 1 carp infected with CEV from genogroup IIa. This was the same sample for which Oyamatsu's end-point PCR assay also failed to provide a positive signal. Therefore, the diagnostic usability of the TiHo qPCR assay is limited to the detection of CEV from genogroups IIa and IIb. The relatively narrow analytical specificity of the TiHo qPCR is related to a point mutation which seems to be characteristic of most of the samples from genogroup I, which is present at the FAM-labelled 5' end of the probe (see Fig. S1 in the Supplement) and which provides a semi-genotyping ability. Together with Oyamatsu's end-point, both of these PCR assays amplify the region of the $p 4 a$ gene that is more divergent (up to $10 \%$ dissimilarities) when genogroups I and IIa are compared (Fig. S1).

The TiHo SYBRGreen qPCR assay had a significantly higher analytical inclusivity and diagnostic sensitivity in samples infected with CEV from genogroup I but also from genogroups IIa and IIb. With this assay, only 1 sample from genogroup I was negative, and that sample had an extremely low virus load when analysed with the CEFAS qPCR assay. The same situation was found with a sample from genogroup IIa, which was also negative using the TiHo SYBRGreen assay but positive using the CEFAS qPCR assay. For 3 samples from this genogroup, the TiHo SYBRGreen PCR also gave a $C_{\mathrm{T}}$ value significantly higher compared to results from the other qPCR assays. This suggests that the TiHo SYBRGreen PCR is suitable for the detection of CEV from all genogroups in most of the samples, but might have a higher detection limit, which may indicate decreased sensitivity in marginally positive samples, compared to the qPCRs based on fluorescencelabelled probes. In our comparison this was the case with a sample bearing sequence \#37, where the TiHo SYBRGreen qPCR was not able to detect CEV DNA (Fig. 1). Furthermore, due to the use of an intercalating dye, interpretation of the results might be more difficult because careful analysis of melting curves is needed. The melting peaks of the products from $\mathrm{CEV}$ genogroups I and IIa occurred at 75.6 and $76.2^{\circ} \mathrm{C}$. These slight differences in melting temperatures were not useful for distinguishing between the genogroups.

In recent years the epidemiological situation involving CEV has developed dynamically, in particular with records from populations of farmed carp in various geographic locations of Europe. The sequence data of $\mathrm{CEV}$ from various places of origin indicate a high degree of genetic diversity and good separation of sequences from genogroups I and IIa (Fig. 1), which might suggest that the virus from genogroup I has been present in the European common carp population for a prolonged period of time, while virus from genogroup IIa could have been repeatedly introduced to European koi populations by the ornamental fish trade from Japan. Indeed, numerous batches of koi imported from Japan were found to be positive for CEV from genogroup IIa (Adamek et al. 2016). However, a model of genetic evolution should be employed to confirm this hypothesis. Furthermore, there is still a lack of knowledge on how many virus variants are present in the fish population. In addition, nothing is known about the virulence of particular genetic variants or how likely they might be as a cause of mortality in the infected population. Recent observations in our laboratory during cohabitation experiments suggest differences in virulence between viruses from different genogroups (Adamek et al. 2017). This underlines the need for a reliable detection method of CEV in carp populations at risk of infection. The determination of virus loads and genogroup provides a further assessment of the clinical relevance of the infection and the likelihood of development of disease. 


\section{CONCLUSIONS}

The comparison of different PCR protocols for the detection of CEV showed that the CEFAS PCRs published by Matras et al. (2017) are the most suitable protocols for detecting viruses from all known CEV genogroups. These assays present high diagnostic sensitivity, and furthermore, they exhibit the highest analytical inclusivity, as the primers were placed in a less divergent fragment of the p4a gene. This makes them candidates for an inclusive screening assay. The genetic diversity of CEV has not been fully explored yet, and our results suggest that there is an urgent need for further characterisation of CEV sequences to identify an amplification target with less genetic variability. Before this is completed, we suggest using both CEFAS protocols, the end-point and the quantitative PCR assays, for routine diagnostics. By applying 2 sets of primers (or even 3 when the nested end-point PCR is used), it is less likely that false negative result will be obtained when novel mutations occur in the $p 4 a$ target sequence currently used for CEV detection.

\section{LITERATURE CITED}

Adamek M, Jung-Schroers V, Hellmann J, Teitge F and others (2016) Concentration of carp edema virus (CEV) DNA in koi tissues affected by koi sleepy disease (KSD). Dis Aquat Org 119:245-251

* Adamek M, Oschilewski A, Wohlsein P, Jung-Schroers V and others (2017) Experimental infections of different carp strains with the carp edema virus (CEV) give insights into the infection biology of the virus and indicate possible solutions to problems caused by koi sleepy

Editorial responsibility: Mark Crane,

Geelong, Victoria, Australia disease (KSD) in carp aquaculture. Vet Res 48:12

Bachmann J, Keilholz S (2016) Frühjahrsverluste in der Fränkischen Karpfenteichwirtschaft - viraler Erreger als Ursache? Erstnachweise der KSD/CEV in Bayern. Fischer \& Teichwirt 03:91-92

Dereeper A, Guignon V, Blanc G, Audic S and others (2008) Phylogeny.fr: robust phylogenetic analysis for the nonspecialist. Nucleic Acids Res 36(Suppl 2):W465-W469

Hedrick RP, Antonio DB, Munn RJ (1997) Poxvirus like agent associated with epizootic mortality in juvenile koi (Cyprinus carpio). FHS Newsletter 25:1-2

* Jung-Schroers V, Adamek M, Teitge F, Hellmann J and others (2015) Another potential carp killer?: Carp edema virus disease in Germany. BMC Vet Res 11:114

* Lewisch E, Gorgoglione B, Way K, El-Matbouli M (2015) Carp edema virus/koi sleepy disease: an emerging disease in central-east Europe. Transbound Emerg Dis 62: 6-12

Matras M, Borzym E, Stone D, Way K and others (2017) Carp edema virus in Polish aquaculture - evidence of significant sequence divergence and a new lineage in common carp Cyprinus carpio (L.). J Fish Dis 40:319-325

Miyazaki T, Isshiki T, Katsuyuki H (2005) Histopathological and electron microscopy studies on sleepy disease of koi Cyprinus carpio koi in Japan. Dis Aquat Org 65:197-207

Oyamatsu T (1996) Study on edema disease of carp. PhD dissertation No. 142, Tokyo University of Fisheries (In Japanese) http://id.nii.ac.jp/1342/00000816/

Oyamatsu T, Matoyama H, Yamamoto K, Fukuda H (1997) A trial for detection of carp edema virus by using polymerase chain reaction. Suisan Zoshoku 45:247-251

* Swaminathan TR, Kumar R, Dharmaratnam A, Basheer VS and others (2016) Emergence of carp edema virus (CEV) in cultured ornamental koi carp, Cyprinus carpio koi in India. J Gen Virol 97:3392-3399

Way K, Stone D (2013) Emergence of carp edema virus-like (CEV-like) disease in the UK. CEFAS Finfish News 15: 32-34

Khang X, Ni Y, Ye J, Xu H, Hou Y, Luo W, Shen W (2017) Carp edema virus, an emerging threat to the carp (Cyprinus carpio) industry in China. Aquaculture 474:34-39

Submitted: February 21, 2017; Accepted: July 5, 2017

Proofs received from author(s): August 21, 2017 